\section{Visual outcome after open globe injury: a comparison of two prognostic models - the Ocular Trauma Score and the Classification and Regression Tree}

C Yu Wai Man and D Steel
Department of

Ophthalmology, Sunderland Eye Infirmary, Sunderland, Tyne and Wear, UK

\section{Correspondence:}

C Yu Wai Man,

Department of

Ophthalmology,

Sunderland Eye Infirmary,

Queen Alexandra Road,

Sunderland,

Tyne and Wear SR2 9HP, UK

Tel: + 44 1912414508;

Fax: +44 1915140220.

E-mail: cynthiayuwaiman@

hotmail.co.uk

Received: 2 September 2008

Accepted in revised form:

12 January 2009

Published online: 20

February 2009

\begin{abstract}
Aims To compare the ocular trauma score (OTS) and the classification and regression tree (CART) as prognostic models of visual outcome after open globe injury.

Methods A retrospective review of $\mathbf{1 0 0}$ consecutive open globe injuries at the Sunderland Eye Infirmary was conducted from January 1999 to December 2007. Univariate chi-square analysis was used to identify the variables associated with visual outcome. We compared the CART and OTS predictions with the actual visual outcomes and calculated the sensitivity and specificity of each model.

Results The variables most predictive of visual loss were an RAPD, poor initial vision, lid laceration, posterior wound, and globe rupture. The sensitivity to predict visual survival (LP or better) was $\mathbf{9 7 . 4 \%}$ for OTS and 93.5\% for CART. The specificity to predict no vision (NPL or enucleation) was $100 \%$ for OTS and $73.9 \%$ for CART. The sensitivity to predict minimal-to-severe visual loss ( $3 / 60$ or better) was $\mathbf{9 0 . 9 \%}$ for OTS and $\mathbf{8 5 . 7 \%}$ for CART. The specificity to predict profound visual loss (worse than $3 / 60$ ) was $100 \%$ for OTS and $81.8 \%$ for CART.

Conclusions We identified several factors that can help in deciding on the prognostic value of primary globe repair. Both the OTS and CART had high predictive accuracy, but the OTS had higher prognostic accuracy and could be used in counselling patients and in management decision-making.
\end{abstract}

Eye (2010) 24, 84-89; doi:10.1038/eye.2009.16; published online 20 February 2009

Keywords: open globe injury; penetrating eye injury; prognosis; enucleation

\section{Introduction}

Open globe injuries are a major cause of permanent visual impairment and blindness. They have an estimated global incidence rate of 3.5 per 100000 persons per year, leading to $\sim 203000$ open globe injuries per year worldwide. ${ }^{1}$ The incidence rates of ocular trauma requiring hospitalisation are reported to be 8.1 per 100000 persons per year in Scotland, ${ }^{2}$ 12.6 per 100000 persons per year in Singapore, ${ }^{3}$ 13.2 per 100000 persons per year in the United States, ${ }^{4}$ and 15.2 per 100000 persons per year in Australia. ${ }^{5}$

Several studies have suggested that the factors that significantly predict visual outcome after open globe injuries are initial visual acuity, ${ }^{6,7}$ presence of a relative afferent pupillary defect (RAPD), ${ }^{7,8}$ mechanism of injury, ${ }^{7,9,10}$ wound location, $, 11,12$ adnexal trauma, ${ }^{8,13}$ lens damage, ${ }^{7,12}$ hyphaema, ${ }^{14}$ vitreous haemorrhage, ${ }^{11,15}$ and retinal detachment. ${ }^{11,16}$

In 2002, Kuhn et $a l^{17}$ developed a prognostic model, the ocular trauma score (OTS), to predict the visual outcome of patients after ocular trauma. They analysed over 2500 eye injuries from the United States and Hungarian Eye Injury Registries, and evaluated more than 100 variables to identify these predictors. The OTS is calculated by assigning certain numerical raw points to six variables: initial visual acuity, globe 
rupture, endophthalmitis, perforating injury, retinal detachment, and an RAPD. The scores are stratified into five categories that give the probabilities of attaining a range of visual acuities post-injury.

More recently, in 2008, Schmidt et al proposed another prognostic model, the classification and regression tree (CART), to predict visual outcome in patients after open globe injuries. ${ }^{18}$ They analysed 214 patients with open globe injuries at the Wilmer Ophthalmological Institute and constructed a classification tree using binary recursive partitioning. In the classification tree, the presence of an RAPD and poor initial visual acuity were the most predictive of visual loss; the presence of lid laceration and posterior wound location also predicted poor visual outcome.

Both models aimed to predict visual outcome after ocular trauma to guide both clinicians and patients in decision-making. Our aim in this study was to identify the factors that significantly predicted visual outcome after open globe injuries in a major UK centre and to compare the OTS and CART as prognostic models of visual outcome.

\section{Materials and methods}

A retrospective review of all patients with open globe injuries who sought treatment at the Sunderland Eye Infirmary was conducted from January 1999 to December 2007. Cases were identified from the computerised admissions database and case notes were examined to determine patient's age and gender, wound location, and the mechanism and cause of injury.
The mechanism of injury was classified as rupture or laceration, according to the Birmingham Eye Trauma Terminology (BETT) system. ${ }^{19}$ Wound location was defined using the Ocular Trauma Classification Group. ${ }^{20}$ Zone I injuries were confined to the cornea, zone II injuries involved the anterior $5 \mathrm{~mm}$ of the sclera, and zone III injuries involved full-thickness scleral defects more posterior than $5 \mathrm{~mm}$ from the limbus.

The presenting visual acuity and clinical signs (the presence of an RAPD, rupture, endophthalmitis, perforation, retinal detachment, intraocular foreign body, and lid laceration) were recorded. The method of primary repair and any secondary procedures were documented. Follow-up data, including best-corrected visual acuity of at least 6 months, follow-up and complications, were also recorded.

\section{Univariate analysis}

Univariate chi-square analysis was performed on the variables age, gender, cause of injury, mechanism of injury, wound location, initial visual acuity, an RAPD, endophthalmitis, retinal detachment, and lid laceration to determine which ones of these were related to visual outcome.

\section{The CART}

We used the CART model to predict visual survival (LP or better) vs no vision (NPL or enucleation) (Figure 1). ${ }^{18}$ In this model, the absence of an RAPD was the best predictor of visual survival. If there was an RAPD, the next variable was the initial visual acuity. An initial

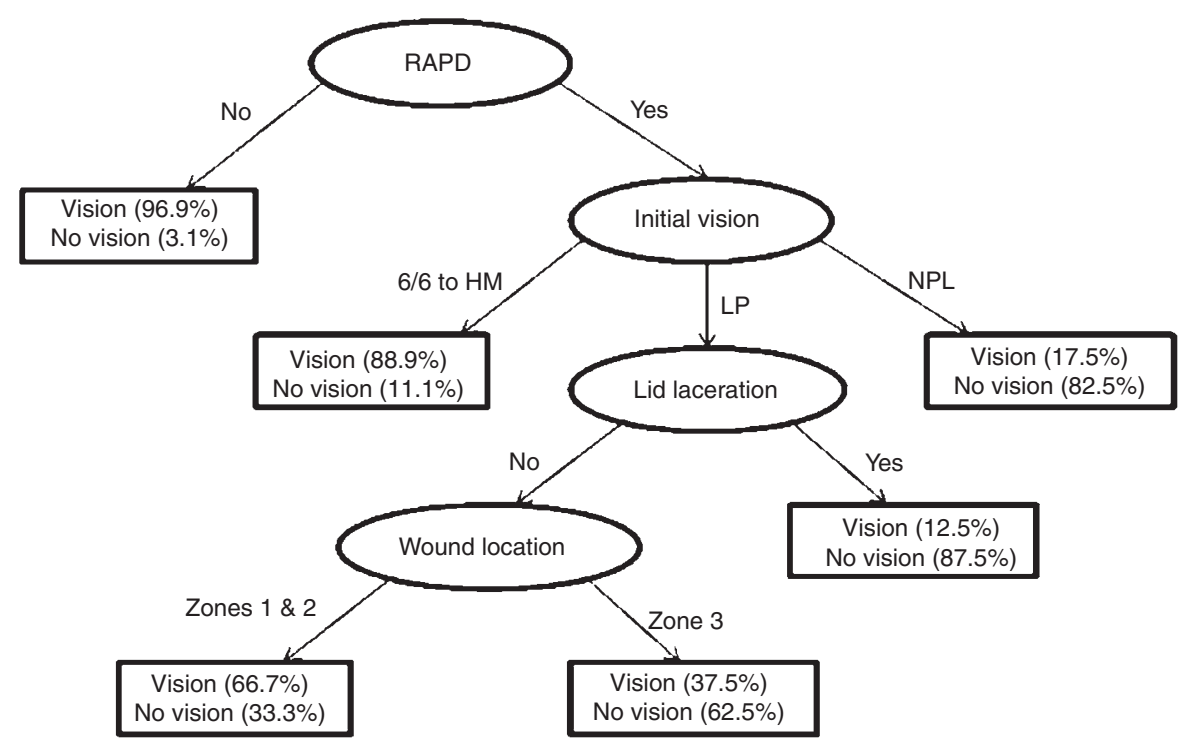

Figure 1 The classification and regression tree (CART) model for open globe injuries: visual survival (LP or better) vs no vision (NPL or enucleation). 
visual acuity of NPL predicted no vision, whereas an initial visual acuity of HM or better predicted visual survival. If the initial visual acuity was LP, the presence of a lid laceration predicted no vision. If there was no lid laceration, anterior wound location predicted a better visual outcome.

We then used the modified CART model to predict minimal to severe visual loss $(6 / 6-3 / 60)$ vs profound visual loss (worse than $3 / 60$ ). In this model, the presence of an RAPD was the best predictor of profound vision loss. If there was no RAPD, the next variable was the initial visual acuity. An initial visual acuity between $6 / 6$ and $3 / 60$ predicted minimal to severe visual loss. If the initial visual acuity was worse than $3 / 60$, the presence of globe rupture and age older than 38.5 years predicted profound vision loss.

We compared the predictions with the actual visual outcomes and calculated the sensitivity and specificity of the CART model (visual survival vs no vision) and the modified CART model (minimal to severe visual loss vs profound visual loss).

\section{The OTS}

We used the OTS to predict the visual outcome in all patients. ${ }^{17}$ The OTS score was calculated by assigning a raw point value for the initial visual acuity and then subtracting the appropriate raw points for each diagnosis of globe rupture, endophthalmitis, perforating injury, retinal detachment, and an RAPD (Table 1). The scores were grouped into five categories and each category gave a prediction of the patient's probability of attaining a specific visual acuity at a 6-month follow-up.

We compared the predictions with the actual visual outcomes and calculated the sensitivity and specificity of the OTS model to predict visual survival (LP or better) vs no vision (NPL or enucleation), and minimal to severe

Table 1 Calculating the ocular trauma score (OTS): variables and raw points

\begin{tabular}{lc}
\hline Variables & Raw points \\
\hline Initial vision & \\
$\quad$ NPL/enucleation/evisceration & 60 \\
LP/HM & 70 \\
$1 / 60-5 / 60$ & 80 \\
$6 / 60-6 / 15$ & 90 \\
$\geqslant 6 / 12$ & 100 \\
Rupture & -23 \\
Endophthalmitis & -17 \\
Perforating injury & -14 \\
Retinal detachment & -11 \\
RAPD & -10 \\
\hline
\end{tabular}

visual loss $(6 / 6-3 / 60)$ vs profound visual loss (worse than $3 / 60)$.

\section{Results}

We identified 100 consecutive patients with open globe injuries from January 1999 to December 2007. There were $74 \%$ males and $26 \%$ females. The age of the patients ranged from 2 to 97 years, with a mean of 36 years. The majority of the injuries were caused by accidents (81\%) and assault was responsible for $19 \%$ of the injuries. Forty patients had globe ruptures and 60 patients sustained globe lacerations (28 penetrating injuries, 25 intraocular foreign bodies, and 7 perforating injuries). Most patients $(66 \%)$ had zone I injuries, $22 \%$ had zone II injuries, and $12 \%$ had zone III injuries.

The presenting visual acuity was $6 / 12$ or better in $14 \%$ of patients, $6 / 60-6 / 15$ in $18 \%$ of patients, $1 / 60-5 / 60$ in $11 \%$ of patients, LP or HM in $42 \%$ of patients, and NPL in $15 \%$ of patients. An RAPD was present in $33 \%$ of patients, and $24 \%$ of patients had lid lacerations. All patients had a primary repair of their open globe injury and eight patients had retinal detachments that were managed with a secondary vitrectomy procedure. Two patients developed endophthalmitis and had poor visual outcome despite maximal treatment, with one requiring enucleation and the other achieving HM after long-term follow-up. There were no cases of sympathetic ophthalmitis found during follow-up.

All patients had a minimum of 6 months follow-up (range 6-30 months) and the mean follow-up period was 16.7 months. The final visual acuity was $6 / 12$ or better in $39 \%$ of patients, $6 / 60-6 / 15$ in $17 \%$ of patients, $1 / 60-5 /$ 60 in $4 \%$ of patients, LP or HM in $17 \%$ of patients, and NPL in $9 \%$ of patients, and the enucleation rate was $14 \%$.

\section{Univariate analysis}

The following variables were associated with a no vision outcome: an RAPD $(P<0.0001)$, worse initial visual acuity $(P<0.0001)$, lid laceration $(P=0.0001)$, posterior wound location $(P=0.0041)$, globe rupture $(P=0.0286)$, and assault injury $(P=0.037)$ (Table 2$)$. We did not find statistically significant associations between visual outcome and endophthalmitis $(P=0.4089)$ or retinal detachment $(P=1.00)$.

\section{The CART}

The CART model predicted correctly visual survival (LP or better) in 72 out of 77 patients and no vision (NPL or enucleation) in 17 out of 23 patients (Table 3). The CART 
Table 2 Correlation between patient characteristics and visual outcome

\begin{tabular}{|c|c|c|c|c|}
\hline & $\begin{array}{l}\text { Vision survival } \\
\quad(\mathrm{n}=77)\end{array}$ & $\begin{array}{c}\text { No vision } \\
(\mathrm{n}=23)\end{array}$ & $\begin{array}{l}\text { Odds } \\
\text { ratio }\end{array}$ & P-value \\
\hline \multicolumn{5}{|l|}{ Gender } \\
\hline Male & $58(75.3 \%)$ & $16(69.6 \%)$ & & \\
\hline Female & $19(24.7 \%)$ & $7(30.4 \%)$ & 1.34 & 0.5953 \\
\hline \multicolumn{5}{|l|}{ Age } \\
\hline $0-16$ & $21(27.3 \%)$ & $3(13.0 \%)$ & & 0.5692 \\
\hline $17-39$ & $26(33.8 \%)$ & $9(39.1 \%)$ & & \\
\hline $40-59$ & $20(26.0 \%)$ & $7(30.4 \%)$ & & \\
\hline$\geqslant 60$ & $10(13.0 \%)$ & $4(17.4 \%)$ & & \\
\hline \multicolumn{5}{|l|}{ Cause of injury } \\
\hline Assault & $11(14.3 \%)$ & $8(34.8 \%)$ & 3.2 & 0.037 \\
\hline Accident & $66(85.7 \%)$ & $15(65.2 \%)$ & & \\
\hline \multicolumn{5}{|l|}{ Initial VA } \\
\hline NPL & $1(1.3 \%)$ & $14(60.9 \%)$ & & $<0.0001$ \\
\hline $\mathrm{LP} / \mathrm{HM}$ & $34(44.2 \%)$ & $8(34.8 \%)$ & & \\
\hline $1 / 60-5 / 60$ & $10(13.0 \%)$ & $1(4.3 \%)$ & & \\
\hline $6 / 60-6 / 15$ & $18(23.4 \%)$ & 0 & & \\
\hline$\geqslant 6 / 12$ & $14(18.2 \%)$ & 0 & & \\
\hline \multicolumn{5}{|c|}{ Mechanism of injury } \\
\hline Rupture & $26(33.8 \%)$ & $14(60.9 \%)$ & 3.05 & 0.0286 \\
\hline Laceration & $51(66.2 \%)$ & $9(39.1 \%)$ & & \\
\hline \multicolumn{5}{|l|}{ Location } \\
\hline Zone I & $56(72.7 \%)$ & $10(43.5 \%)$ & & \\
\hline Zone II & $16(20.8 \%)$ & $6(26.1 \%)$ & & \\
\hline Zone III & $5(6.5 \%)$ & $7(30.4 \%)$ & & 0.0041 \\
\hline \multicolumn{5}{|l|}{$R A P D$} \\
\hline Yes & $12(15.6 \%)$ & $21(91.3 \%)$ & 56.88 & $<0.0001$ \\
\hline No & $65(84.4 \%)$ & $2(8.7 \%)$ & & \\
\hline \multicolumn{5}{|c|}{ Endophthalmitis } \\
\hline Yes & $1(1.3 \%)$ & $1(4.3 \%)$ & 3.46 & 0.4089 \\
\hline No & $76(98.7 \%)$ & $22(95.7 \%)$ & & \\
\hline \multicolumn{5}{|c|}{ Retinal detachment } \\
\hline Yes & $6(7.8 \%)$ & $2(8.7 \%)$ & 1.13 & 1 \\
\hline No & $71(92.2 \%)$ & $21(91.3 \%)$ & & \\
\hline \multicolumn{5}{|l|}{ Lid laceration } \\
\hline Yes & $11(14.3 \%)$ & $13(56.5 \%)$ & 7.8 & 0.0001 \\
\hline No & $66(85.7 \%)$ & $10(43.5 \%)$ & & \\
\hline
\end{tabular}

model had $93.5 \%$ sensitivity to predict visual survival and $73.9 \%$ specificity to predict no vision.

The modified CART model predicted correctly minimal to severe visual loss $(6 / 6-3 / 60)$ in 48 out of 56 patients and profound visual loss (worse than 3/60) in 36 out of 44 patients (Table 3 ). The modified CART model had $85.7 \%$ sensitivity to predict minimal to severe visual loss and $81.8 \%$ specificity to predict profound vision loss.
Table 3 The classification and regression tree (CART) analysis predictions compared with the actual visual outcomes

\begin{tabular}{lcc}
\hline & \multicolumn{2}{c}{ Actual outcome } \\
\cline { 2 - 3 } & Visual survival & No vision \\
\hline $\begin{array}{l}\text { CART predicts visual survival } \\
\text { (LP or better) }\end{array}$ & 72 & 6 \\
$\begin{array}{l}\text { CART predicts no vision } \\
\text { (NPL/enucleation) }\end{array}$ & 5 & 17 \\
& $\begin{array}{c}\text { Minimal to severe } \\
\text { visual loss }\end{array}$ & $\begin{array}{c}\text { Profound } \\
\text { visual loss }\end{array}$ \\
\hline $\begin{array}{l}\text { CART predicts minimal to } \\
\text { severe visual loss }(6 / 6-3 / 60)\end{array}$ & 48 & 8 \\
$\begin{array}{l}\text { CART predicts profound } \\
\text { visual loss (worse than 3/60) }\end{array}$ & 8 & 36 \\
\hline
\end{tabular}

Table 4 The ocular trauma score (OTS) predictions compared with the actual visual outcomes

\begin{tabular}{lcc}
\hline & \multicolumn{2}{c}{ Actual outcome } \\
\cline { 2 - 3 } & Visual survival & No vision \\
\hline $\begin{array}{l}\text { OTS predicts visual survival } \\
\text { (LP or better) }\end{array}$ & 75 & 0 \\
$\begin{array}{l}\text { OTS predicts no vision } \\
\text { (NPL/enucleation) }\end{array}$ & 2 & 23 \\
& $\begin{array}{c}\text { Minimal to severe } \\
\text { visual loss }\end{array}$ & $\begin{array}{c}\text { Profound } \\
\text { visual loss }\end{array}$ \\
$\begin{array}{l}\text { OTS predicts minimal to } \\
\text { severe visual loss (6/6/-3/60) }\end{array}$ & 50 & 0 \\
$\begin{array}{l}\text { OTS predicts profound visual } \\
\text { loss (worse than 3/60) }\end{array}$ & 5 & 45 \\
\hline
\end{tabular}

\section{The OTS}

The OTS predicted correctly visual survival (LP or better) in 75 out of 77 patients and no vision (NPL or enucleation) in 23 out of 23 patients (Table 4). It had $97.4 \%$ sensitivity to predict visual survival and $100 \%$ specificity to predict no vision.

The OTS predicted correctly minimal to severe visual loss $(6 / 6-3 / 60)$ in 50 out of 55 patients and profound visual loss (worse than 3/60) in 45 out of 45 patients (Table 4). It had $90.9 \%$ sensitivity to predict minimal to severe visual loss and $100 \%$ specificity to predict profound vision loss.

\section{Discussion}

This study showed that the absence of an RAPD was a key predictor of visual survival $(P<0.0001)$. Rahman et $a l^{8}$ found that the presence of an RAPD was strongly associated with poor visual outcome with $32 \%$ of these patients requiring enucleation. In the CART model, the absence of an RAPD led to $96.9 \%$ chance of visual survival and $3.1 \%$ of no vision. ${ }^{18}$ In concurrence with the 
CART study, out of the 67 patients without an RAPD in our series, 65 patients $(97.0 \%)$ had visual survival and 2 patients $(3.0 \%)$ had no vision. This further stresses the importance of correctly assessing pupil responses and the presence of an RAPD while examining patients with open globe injuries.

Initial visual acuity was also a strong predictor of visual outcome in our study $(P<0.0001)$. In our series, an initial visual acuity of NPL was associated with poor visual outcome, accounting for $60.9 \%$ of the no-vision group and only $1.3 \%$ of the vision survival group. Groessl et $a l^{6}$ described in their study of 42 patients with penetrating ocular injuries that an initial visual acuity of LP or worse was associated with poor visual outcome. In contrast, all patients with an initial visual acuity of $6 / 60$ or better in our series had visual survival. In their review of 290 open globe injuries, Pieramici et $a l^{7}$ reported that none of the patients presenting with a visual acuity better than $1 / 60$ underwent enucleation, whereas $34 \%$ of those with an initial visual acuity worse than 1/60 were enucleated.

In our series, we also found that lid laceration, which is often a marker of adnexal injury from trauma caused by blunt objects, was strongly associated with visual loss $(P=0.0001)$. This makes sense clinically, as injuries caused by blunt objects tend to present with complex corneo-scleral ruptures and posterior globe injuries. Hatton et $a l^{13}$ described in a review of 300 patients with open globe trauma that adnexal injury was associated with worse visual acuity at presentation and an increased likelihood of posterior globe injuries. In a series of 107 open globe injuries, Rahman et $a l^{8}$ also reported that lid lacerations and adnexal trauma were associated with worse visual outcome and a higher rate of enucleation.

Posterior wound location was also a predictor of visual loss in our study $(P=0.0041){ }^{6,7,11,12}$ This would be expected clinically, as posterior segment injury can cause irreversible damage to the retina and optic nerve and thus carry a poor visual prognosis, even after the structural integrity of the globe has been repaired. This view is supported by Johnston who found in his review of 376 open globe injuries that posterior wound location was associated with a poor visual outcome. ${ }^{21}$

Clinicians and patients are faced with a number of decisions after severe open globe injuries. These decisions are based on the prospects of globe and visual preservation after the injury and the degree of visual preservation likely. The preservation of the globe and the risks of sympathetic ophthalmitis also influence the decisions of undertaking primary repair and subsequent revision surgery. Our standard practice, similar to many ophthalmologists worldwide, is to attempt as soon as possible a primary surgical repair of open globe injuries to try to restore the structural integrity of the globe, regardless of the severity of the injury or presenting visual acuity. Enucleation is usually considered subsequently only in cases of severely traumatised globes with no visual potential.

Our enucleation rate of $14 \%$ is similar to the ones reported in the literature by Rofail et al ${ }^{22}$ (15\%), Rahman et $a l^{8}(12 \%)$, and Dunn et $a l^{9}(11 \%)$, but is much lower than the enucleation rates reported by Schmidt et al ${ }^{18}$ (26\%), Pieramici et $\mathrm{al}^{7}$ (24\%), and Casson et $\mathrm{al}^{23}$ (20\%). Certain types of severe open globe injuries, however, carry a poor visual prognosis regardless of how promptly and extensively they are repaired. An eye after primary repair with no visual potential is also sometimes considered for early enucleation in an attempt to reduce the risks of sympathetic ophthalmitis. However, the decision to enucleate the eye should not be rushed and patients need to be appropriately counselled about visual outcomes to help them make an intelligent, informed decision regarding enucleation.

These clinical dilemmas were to influence the development of the two ocular trauma prognostic models. This is the first study we are aware of that compares the two prognostic models, the OTS and the CART, to predict visual outcome after open globe injuries in a major UK centre. We found that the OTS and the CART models both had high sensitivities and specificities to predict correctly visual survival (LP or better) vs no vision (NPL or enucleation) and minimal to severe visual loss $(3 / 60$ or better) vs profound visual loss (worse than $3 / 60$ ), but that the OTS model was more sensitive and specific than the CART model.

The OTS study analysed over 2500 eye injuries from the United States and Hungarian Eye Injury Registries and evaluated more than 100 variables to identify the six predictors, whereas the CART study analysed 214 open globe injuries at the Wilmer Ophthalmological Institute to construct its classification tree. The CART classification tree was constructed using binary recursive partitioning, but there is no description of the statistical methods used in the OTS model in the published literature.

In the CART study, the presence of an RAPD and poor initial visual acuity were the most predictive of visual loss; the presence of lid laceration and posterior wound location also predicted poor visual outcome. In concurrence with the CART model, the presence of an RAPD $(P<0.0001)$, poor initial visual acuity $(P<0.0001)$, lid laceration $(P=0.0001)$, and posterior wound location $(P=0.0041)$ all had statistically significant associations with a no-vision outcome in our series.

The OTS model used six variables (initial visual acuity, an RAPD, globe rupture, endophthalmitis, perforating injury, and retinal detachment) to predict the visual outcome of patients after ocular trauma. In our univariate analysis, initial visual acuity $(P<0.0001)$, an 
RAPD $(P<0.0001)$, and globe rupture $(P=0.0286)$ had statistically significant associations with visual outcome. We, however, did not find statistically significant associations between visual outcome and endophthalmitis $(P=0.4089)$ or retinal detachment $(P=1.00)$ in our study. This was probably because of our relatively small number of endophthalmitis and retinal detachment cases.

The OTS model is easy to use and its six predictors (initial visual acuity, an RAPD, globe rupture, endophthalmitis, perforating injury, and retinal detachment) are readily available. The OTS score can also be calculated on the US Eye Injury website (www.useironline.org). The OTS provides the treating ophthalmologist with realistic expectations of the visual potential of an open globe injury and thus in deciding among various management plans. In this study, the OTS had a higher prognostic accuracy than the CART model to predict correctly (1) visual survival (LP or better) vs no vision (NPL or enucleation), and (2) minimal to severe visual loss (3/60 or better) vs profound visual loss (worse than $3 / 60$ ). We recommend its use by ophthalmologists to appropriately counsel patients and to assist them in making informed treatment decisions.

\section{References}

1 Negrel AD, Thylefors B. The global impact of eye injuries. Ophthalmic Epidemiol 1998; 5: 143-169.

2 Desai P, MacEwen CJ, Baines P. Incidence of cases of ocular trauma admitted to hospital and incidence of blinding outcome. Br J Ophthalmol 1996; 80: 592-596.

3 Wong TY, Tielsch JM. A population-based study on the incidence of severe ocular trauma in Singapore. $A m \mathrm{~J}$ Ophthalmol Clin North Am 1999; 128: 345-351.

4 Klopfer J, Tielsch JM, Vitale S. Ocular trauma in the United States: eye injuries resulting in hospitalization, 1984 through 1987. Arch Ophthalmol 1992; 110: 838-842.

5 Fong LP. Eye injuries in Victoria, Australia. Med J Aust 1995; 162: 64-68.

6 Groessl S, Nanda SK, Mieler WF. Assault-related penetrating ocular injury. Am J Ophthalmol 1993; 116: 26-33.
7 Pieramici DJ, MacCumber MW, Humayun MU. Open globe injuries. Update on types of injuries and visual results. Ophthalmology 1996; 103: 1798-1803.

8 Rahman I, Maino A, Devadason D. Open globe injuries: factors predictive of poor outcome. Eye 2006; 20: 1336-1341.

9 Dunn ES, Jaeger EA, Jeffers JB. The epidemiology of ruptured globes. Ann Ophthalmol 1992; 24: 405-410.

10 Gilbert CM, Soong HK, Hirst LW. A two-year prospective study of penetrating ocular trauma at the Wilmer Ophthalmological Institute. Ann Ophthalmol 1987; 19: 104-106.

11 Brinton GS, Aaberg TM, Reeser FH. Surgical results in ocular trauma involving the posterior segment. Am J Ophthalmol 1982; 93: 271-278.

12 Sternberg P, de Juan E, Michels RG. Multivariate analysis of prognostic factors in penetrating ocular injuries. Am J Ophthalmol 1984; 98: 467-472.

13 Hatton MP, Thakkar MM, Ray S. Orbital and adnexal trauma associated with open globe injuries. Ophthalmol Plastic Reconstr Surg 2002; 18: 458-461.

14 Barr CC. Prognostic factors in corneoscleral lacerations. Arch Ophthalmol 1983; 101: 919-924.

15 de Juan E, Sternberg P, Michels RG. Penetrating ocular injuries: types of injuries and visual results. Ophthalmology 1983; 90: 1318-1322.

16 Martin DF, Meredith TA, Topping TM. Perforating (through-and-through) injuries of the globe: surgical results with vitrectomy. Arch Ophthalmol 1991; 109: 951-956.

17 Kuhn F, Maisiak R, Mann L. The ocular trauma score (OTS). Ophthalmol Clin North Am 2002; 15: 163-165.

18 Schmidt GW, Broman AT, Hindman HB. Vision survival after open globe injury predicted by classification and regression tree analysis. Ophthalmology 2008; 115: 202-209.

19 Kuhn F, Morris F, Witherspoon CD. The Birmingham Eye Trauma Terminology system (BETT). J Fr Ophthalmol 2004; 27: 206-210.

20 Pieramici DJ, Sternberg P, Aaberg TM. A system for classifying mechanical injuries of the eye (globe). Am J Ophthalmol Clin North Am 1997; 123: 820-831.

21 Johnston S. Perforating eye injuries: a five year survey. Trans Ophthalmol Soc UK 1971; 91: 895-921.

22 Rofail M, Lee GA, O’Rourke P. Prognostic indicators for open globe injury. Clin Experiment Ophthalmol 2006; 34: 783-786.

23 Casson RJ, Walker JC, Newland HS. Four-year review of open eye injuries at the Royal Adelaide Hospital. Clin Experiment Ophthalmol 2002; 30: 15-18. 